\title{
Licenciatura em Computação e Profissionalidade Docente
}

\author{
Heloisa Salles Gentil \\ Universidade do Estado de Mato Grosso, MT-Brasil. \\ logentil@ibest.com.br \\ André Luiz Borges Milhomem \\ Universidade do Estado de Mato Grosso, Colíder, MT - Brasil. \\ andre80@unemat.br
}

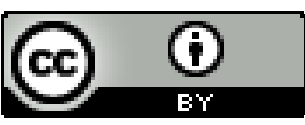

Educação: teoria e prática, Rio Claro, SP, Brasil - eISSN: 1981-8106

Está licenciada sob Licença Creative Common

\section{Resumo}

O objetivo deste trabalho é analisar questões relativas à profissionalização e profissionalidade docente no que se refere à Licenciatura em Computação. Este estudo foi realizado a partir da análise de alguns aspectos das matrizes curriculares de cursos de Licenciatura em Computação da UNEMAT, elementos da legislação e do contexto em que se inserem esses cursos e de discussões atuais acerca do profissional professor de Computação. As normas que orientam essa formação e as propostas curriculares apresentam contradições: o curso é uma licenciatura, mas a definição do perfil profissional não se restringe à docência; os egressos serão professores da Educação Básica, mas não há esse campo de atuação ou disciplina previsto em sua organização; apenas para o Ensino Médio, são indicados conhecimentos, competências e habilidades na área de Informática. As propostas de formação analisadas (Diretrizes para Formação de Professores e a proposta curricular da Sociedade Brasileira de Computação) se orientam pela demanda da sociedade contemporânea de profissionais flexíveis, aptos a atuar em mais de um campo de trabalho, dificultando a constituição da profissionalidade docente e o papel dos cursos de formação inicial em sua tarefa de contribuir para a profissionalização da profissão professor.

Palavras chaves: Formação de professores. Licenciatura em computação. Profissionalidade docente.

\section{Degree in Computing and Teaching Professionality}

\author{
Abstract \\ The objective of this project is analyse related issues to the profissionalization and teaching \\ professionality in which refers to Degree in Computing. This study was conducted from the
}


analysis of some curricular matrices elements in courses of Degree in Computing in development at UNEMAT, in Cáceres and Colider, of legislation items concerning, and the context of these courses and of the current discussions about the professional computing teacher. The standards that guide this formation and curricular proposals present contradictions: the course is a graduation, but the definition of the professional profile is not restricted to teaching; the graduates will be teacher of Basic Education, but there's not this field of action or discipline provided in the parameters that guide the teaching organization, unless in highschool, in whose PCNs are provided knowledges, competences and abilities in the Computers area. The professional formation proposals that were analysed, both the Guidelines for Teacher Training and the curriculum of the Brazilian Computer Society, showed theyself oriented by "flexible" professionals demanded by the contemporary society, they have to be able to act in more of a working field. It makes difficult the constitution of the teaching professionalism and the function of initial formation courses in the task of contributing for the profissionalization of the teacher profession.

Keywords: Teacher training. Degree in computing. Teaching professionality.

\section{Introdução}

Este trabalho tem como objetivo problematizar questões relativas à profissionalização e profissionalidade docente na licenciatura em Computação, a partir do estudo de duas matrizes curriculares em desenvolvimento em uma universidade multicampi, do contexto mais amplo em que se inserem e das discussões acerca do profissional professor de Computação/Informática.

O tema em questão é abordado a partir do conceito de profissão, formulado com base em campo de conhecimento específico, autonomia, controle pelos pares, identidade; trata-se da profissão professor. Profissionalidade e profissionalização também são conceitos fundamentais para essa discussão, tendo como referências Sacristán (1995); Lüdke (2004); Ramalho, Nuñez e Gauthier (2004), entre outros.

No contexto de questões relativas à profissão docente é preciso levar em consideração o desenvolvimento tecnológico contemporâneo como elemento marcante no processo de mudanças do mundo do trabalho, da cultura e da sociedade. Segundo Ludke (2004, p.1170), nas escolas, tecnologias levam à criação de postos de trabalho, ao contrário do que ocorre em relação a outros setores, mas esse fato não valoriza a profissão docente em geral; ao contrário, cria um novo grupo de especialistas. O surgimento de uma licenciatura específica de Computação e a demanda dos (recém) profissionais dessa área por um campo próprio de trabalho se inserem na discussão sobre profissão e profissionalidade docente. 
Os cursos de Licenciatura em Computação têm como objetivo a formação de professores para a educação básica, proposição instigante levando em conta essa não ser uma área nem uma disciplina componente do currículo escolar desse nível de ensino de acordo com os Parâmetros Curriculares Nacionais PCNs de 1a a 4a série (1997) e de $5^{a}$ a 8 $^{a}$ (1998), documento base da organização curricular do ensino. Apenas nos PCNs do Ensino Médio (2000), ao se tratar de Linguagens, Códigos e suas Tecnologias, o acesso a conhecimentos na área de Informática é apontado como uma das competências e habilidades a serem desenvolvidas, mas não deixa claro como serão implementadas. $O$ tema gera discussões e ações políticas, tanto por parte dos que defendem, como dos que questionam a existência desse professor na Educação Básica e dessa licenciatura na universidade.

Profissionalidade é "a afirmação do que é específico na ação docente, isto é, o conjunto de comportamentos, conhecimentos, destrezas, atitudes e valores que constituem a especificidade de ser professor" (SACRISTÁN, 1995, p.65). Entre as questões em pauta cabe, então, destacar: qual a especificidade do professor de Computação? Que profissional as licenciaturas em Computação visam formar?

\section{Controvérsias e contradições}

Para discutir as questões propostas é preciso estar atento ao contexto educacional mais amplo no qual elas se colocam: um contexto de mudanças. Camargo e Hage (2004) explicam como as reformas educacionais estão enquadradas no conjunto de reformas e políticas sociais que vem sendo realizadas sob orientação de organismos financeiros internacionais, resultando na adequação dos sistemas de ensino às políticas econômicas.

Nesse processo vem ocorrendo uma naturalização da ideia do espaço universitário como campo de formação profissional para atender ao mercado de trabalho. As relações sociais e de trabalho se tornam mais complexas e contraditórias, exige-se um profissional flexível, apto a exercer mais de uma função; e as instituições de ensino superior têm sido levadas a incorporar essa ideia, oferecendo formação de acordo com essas exigências.

(...) une estes vários segmentos [educadores, estudantes, setores governamentais, organismos internacionais e setores do empresariado nacional] a preocupação com a formação de profissionais com capacidade para responder às necessidades cruciais da sociedade contemporânea. Para que isto venha a ocorrer, entendem que é preciso reformar o sistema educacional de modo que este cumpra a sua 
finalidade de preparação de pessoal com mais competência e objetividade. Um dos focos desta discussão encontra-se precisamente no campo da formação profissional nos cursos de licenciatura. (SETTE; AGUIAR; SETTE, 1997, p.2).

Os cursos de Licenciatura em Computação podem ser tomados como um exemplo de atendimento à demanda e pressão do mercado, bem como da lógica que orienta a reforma educacional em curso no país.

Segundo Nunes (2008), “A Computação é tão ou mais importante que Química, Física, etc. até porque, todo cidadão, no exercício de suas atividades profissionais, seguramente vai aplicar tecnologias da informação." Mas a relação entre TIC (tecnologias da informação e comunicação) e educação tem gerado preocupações:

Não queremos negar que existem vantagens no uso das TIC, porém não devemos
acreditar no seu poder miraculoso ou nos fascinar com a atratividade dos meios de
comunicação e artefatos tecnológicos, sem uma postura crítica sobre os processos
de desterritorialização da escola e de flexibilização e precarização do trabalhador
docente provocado pela onda tecnológica que invade a educação. (AGUIAR, 2009,
p.130).

A inserção do computador na educação geralmente ocorre de acordo com duas linhas conceituais. A primeira prende-se ao ensino da informática, seus fundamentos, suas técnicas, tendo como objetivo alfabetização digital e o preparo para o mercado de trabalho, o domínio do computador é a principal finalidade - informática como fim. A segunda diz respeito ao uso do computador como meio, um aliado para provocar mudanças pedagógicas, um meio facilitador no processo de ensino aprendizagem (ALMEIDA, 2000).

Essa é uma das polêmicas na área de informática na educação, diante da qual Tajra $(2008$, p.54) prefere utilizar a expressão "uso pedagógico e social", pois o enfoque deveria ser: o que fazer para atingir o objetivo definido pela escola em relação à educação e uso de TIC. A autora propõe: "utilização do computador para fins pedagógicos e sociais" (TAJRA, 2008, p.54), ou seja, sem enfatizar a disputa entre uma ou outra finalidade. Nem uma, nem outra definição consta de maneira explícita dos documentos que orientam a formação de professores nessa área.

As Diretrizes Curriculares Nacionais para a Formação de Professores da Educação Básica - Resolução CNE/CP 1, 18/02/2002 - no artigo 2o, inciso VI afirmam “o uso de tecnologias da informação e da comunicação e de metodologias, estratégias e materiais de apoio inovadores" (BRASIL/CNE, 2002, p.1, grifo nosso), como uma das atividades 
necessárias para a formação docente. E, no artigo 3으, inciso II, que, entre os princípios que devem nortear essa formação esteja "a coerência entre a formação oferecida e a prática esperada do futuro professor". E ainda, no artigo 5으, inciso I que "a formação deverá garantir a constituição das competências objetivadas na educação básica". Ou seja, orientam a relação essencial que deve existir entre a formação de professores nas licenciaturas e seu campo de atuação, a educação básica.

De acordo com a proposta das Diretrizes Curriculares para os cursos de Bacharelado em Ciência da Computação, Engenharia de Computação, Engenharia de Software e Sistemas de Informação e cursos de Licenciatura em Computação (http://formularios.mec.gov.br/consulta-diretrizes-curriculares até o final de março de 2011), o objetivo principal dessa licenciatura é a formação de professores para que, por sua vez, formem cidadãos aptos a utilizar o pensamento e as ferramentas relacionadas ao uso de tecnologias; com "habilidades e competências" para "conviver e prosperar" em função de "promover o desenvolvimento econômico e social de nosso País" (BRASIL/MEC, SESU, CEEInf, 2011).

Em busca da relação entre a formação e o campo de atuação do licenciado em Computação, que fundamenta a profissionalidade docente, analisamos, também, neste artigo, aspectos dos PCNs do Ensino Fundamental, publicados em 1997 e 1998, onde se afirma a importância da aprendizagem dos alunos para lidar com as novas tecnologias demandadas pelo contexto atual, mas a Computação não aparece como disciplina ou tema transversal.

Sette, Aguiar e Sette (1997, p.2), analisando as diversas áreas e disciplinas que compõem o currículo escolar atual, questionam:

(...) pode a Informática ser considerada uma nova área de conhecimento? Uma nova disciplina? Tem estatuto epistemológico para tanto? Ou ela representa a evolução de conhecimentos já existentes? Ou seja: o que constitui o objeto de estudo em informática? Qual o papel do professor de informática na escola? De que forma a informática entra na escola?

Criticas a existência de uma disciplina de informática na Educação Básica se fundamentam em questões como essa e levam alguns pesquisadores a se posicionarem contra a existência dessas licenciaturas, afirmando que as tecnologias devem ser parte dos conteúdos curriculares de todas as disciplinas, baseados na ideia de que informática e a 
computação são instrumentos pedagógicos e não um campo de conhecimento, por isso não exigem disciplina ou professor.

Mas há os que indagam se a aprendizagem das TIC tem se dado por meio de outras disciplinas. Defensores da Licenciatura em Computação afirmam, também, a necessidade de um profissional para atuação no laboratório de informática, com formação em áreas pedagógica e computacional, que possa ser um interlocutor/facilitador entre as novas tecnologias e os processos educacionais. Ao transitar entre essas áreas, tal profissional deveria auxiliar a desenvolver, junto à comunidade escolar, formas de utilização das TIC para atender às necessidades de cada comunidade.

Analisando os PCNs 1a a 4a séries do Ensino Fundamental (1997) verifica-se que não descrevem a informática ou a Computação como campo ou área de conhecimentos, ainda que se afirme: "os conteúdos escolares que são ensinados devem, portanto, estar em consonância com as questões sociais que marcam cada momento histórico" (BRASIL, MEC, Livro 1, 1997, p.33). Deduz-se que a perspectiva adotada no documento é a de que a informática ou a computação são instrumentos, meios e não um campo que necessite de disciplinas específicas, como se pode observar:

É indiscutível a necessidade crescente do uso de computadores pelos alunos como instrumento de aprendizagem escolar, para que possam estar atualizados em relação às novas tecnologias da informação e se instrumentalizarem para as demandas sociais presentes e futuras. (BRASIL, 1997, p.67, grifos nossos).

Registre-se que a publicação dos PCNs do Ensino Fundamental se deu no mesmo período em que se iniciava o primeiro curso de Licenciatura em Computação no país, em 1997, na UnB (Universidade de Brasília). Eis aí uma contradição: autoriza-se a abertura de um curso para formar professores de uma área cuja existência não está prevista na Educação Básica, seu campo de atuação por excelência. Ainda assim, segundo o censo realizado pelo Inep, em 2006 já existiam no país setenta cursos de Licenciatura em Computação (NUNES, 2008).

Com relação aos PCNEM (Parâmetros Curriculares Nacionais para o Ensino Médio, 2000) observa-se que a Informática aparece como componente curricular:

Em síntese, a informática encontra-se presente na nossa vida cotidiana e incluí-la como componente curricular da área de Linguagens, Códigos e suas tecnologias 
significa preparar os estudantes para o mundo tecnológico e científico, aproximando a escola do mundo real e contextualizado.

O estudante não deve ser visto apenas como quem usa a informática enquanto instrumento de aprendizagem, mas também como aquele que conhece os equipamentos, programas e conceitos que lhe permitam a integração ao trabalho e o desenvolvimento individual e interpessoal. (BRASIL/PCNEM, 2000, p.61)

De acordo com os PCNEM, a inclusão da informática como componente curricular objetiva "permitir o acesso a todos os que desejam torná-la um elemento de sua cultura, assim como aqueles para os quais a abordagem puramente técnica parece insuficiente para o entendimento de seus mecanismos profundos. [...]" (BRASIL/PCNEM, 2000, p.58).

Amparada nesses pressupostos, a Informática é apontada como uma potencial disciplina, conforme trecho que diz: “As disciplinas potenciais Língua Portuguesa, Língua Estrangeira Moderna, Arte, Educação Física e Informática encontram na área especificidades que sugerem um estudo articulado dos processos comunicativos". (BRASIL/PCNEM, 2000, p.64).

\section{Profissionalidade docente, profissionalização e a formação do licenciado em computação}

A discussão a respeito da profissionalização do professor está em pauta, especialmente, desde a década de 1980 , e não se encerrou. Baseados nos estudos de diversos autores, Ramalho, Nuñez e Gauthier (2004) afirmam a existência de duas dimensões para se tratar de profissionalização: um processo interno (profissionalidade) e outro externo (profissionismo ou profissionalização). Profissionalização

(...) refere-se à reivindicação de um status distinto dentro da visão social do trabalho. Implica em negociações por um grupo de atores, com vistas a fazer com que a sociedade reconheça as qualidades específicas, complexas e difíceis de serem adquiridas, de tal forma que lhes proporcionem não apenas certo monopólio sobre um conjunto de atividades, mas também uma forma de prestígio e de participação nas problemáticas da construção da profissão. (RAMALHO, NUÑEZ e GAUTHIER, 2004, p.52).

A profissionalidade docente pode ser compreendida como um dos aspectos de caráter subjetivo da profissionalização; um "conjunto de características que distingue o trabalho docente" (RAMALHO; NUÑEZ; GAUTHIER, 2004, p.51-52), mas sempre em processo de constituição, de construção de competências para a prática profissional a partir de saberes das disciplinas e saberes pedagógicos já adquiridos. 
Essa discussão está presente nos estudos atuais sobre professores e sua formação; este artigo trata, especificamente, sobre a formação de um tipo de profissional professor, cuja identidade e campo de atuação estão em construção mais recente: o licenciado em computação.

Com base nesses conceitos problematiza-se a formação de professores licenciados em computação, na tentativa de compreender de que profissionalidade se trata nos projetos pedagógicos dos cursos de licenciatura e que processo de profissionalização a graduação inicia, considerando que a formação inicial é ponto de partida, mas não pode ser responsabilizada por toda a profissionalização, que é processo contínuo.

Analisando as Diretrizes que orientam a formação do licenciado em Computação, nota-se que para descrever o perfil do egresso e para determinar as habilidades e competências específicas desse profissional, o argumento determinante é "a flexibilidade necessária para atender domínios diversificados de aplicação e para as vocações das Instituições" (BRASIL/MEC, SESU, CEEInf, 2003, s/p.) Ou seja, o mercado de trabalho e suas atuais condições influenciam na determinação do perfil do licenciado, que se pauta em aplicações variadas do conhecimento da área e na necessidade das diversas instituições. Isso implica o profissional possuir conhecimentos sobre as áreas afins, além de ser capaz de desenvolver tecnologias educacionais "visando ensino aprendizagem assistidos por computador" (BRASIL/MEC, SESU, CEEInf, 2003, s/p).

Entre as três expectativas enunciadas em relação aos egressos, a capacidade de atuar como docente é a última na enumeração apresentada nas Diretrizes. A justificativa parece ser, mais uma vez, a flexibilidade necessária, tanto para os diversos usos (aplicações) possíveis como para as várias instituições em que o licenciado poderá atuar (nem sempre espaços escolares).

Pesquisas têm demonstrado que há contradições expostas nas matrizes curriculares dos cursos de formação de professores de todas as áreas (KRAHE, 2009; GENTIL, 2010; entre outros). No caso em estudo, propostas curriculares dos cursos de Licenciatura em Computação, as contradições são detectadas desde o texto das Diretrizes.

Em “Competências e Habilidades Específicas dos Egressos", no Projeto Pedagógico da licenciatura de Cáceres, fica explícita a flexibilidade da função proposta ao licenciado, cujas competências vão desde a criação, o desenvolvimento, a avaliação de softwares e hardwares 
educacionais até a docência, passando pela coordenação de projetos, administração de laboratórios e a atuação "junto ao corpo docente das Escolas nos níveis da Educação Básica e Técnico e suas modalidades e demais Organizações no uso efetivo e adequado das tecnologias da educação" (BRASIL/MEC, SESU, CEEInf, 2003, s/p). Essa última função pode ser compreendida como formação de professores para o uso das TIC. Em síntese, a expectativa é a de um profissional flexível, com múltiplas habilidades e capaz de desempenhar as mais variadas funções.

Se, por um lado, essa flexibilidade aparece como ponto positivo no sentido de atendimento à demanda atual do mercado de trabalho, por outro essa situação configura-se problemática no que diz respeito à constituição da profissionalidade desse docente: qual a especificidade profissional do licenciado em computação?

A polêmica a respeito dessa formação não se encerrou com a criação e expansão de cursos de licenciatura na área específica. Em busca de aprofundar essa discussão sob a ótica da profissionalidade docente, a partir desses cursos e desses profissionais, analisaram-se dois projetos pedagógicos (PPs), evidenciando o profissional que se pretende formar e seu campo de atuação, ou seja, como esses cursos esboçam e objetivam o licenciado em Computação. Foi dada atenção especial ao estágio, pois é considerado o espaço específico para experiência profissional orientada, na qual o acadêmico entra em contato com a realidade de seu campo profissional.

A universidade em foco (UNEMAT) é pública, estadual, e tem uma história ligada à formação de professores, assumindo compromissos com o Estado nos projetos e nas políticas que visam atender especialmente a essa demanda.

Foram analisados aspectos dos PPs do curso de Licenciatura em Computação do Campus Jane Vanini, Cáceres/MT e do campus Vale do Teles Pires, Colíder/MT, ambos pautados nas Diretrizes Curriculares de Cursos da área de Computação e Informática e de pareceres da Comissão de Especialistas de Ensino de Computação e Informática do Ministério da Educação (CEEInf/MEC). As matrizes curriculares estão baseadas nas normas da Sociedade Brasileira de Computação (2002) e nos Pareceres CNE/CP 1 e 2 (2002).

Os dois cursos estão organizados com base nos seguintes núcleos: 1. Formação geral, que congrega um conjunto de conhecimentos básicos das ciências humanas; 2. Formação Básica em Computação, um conjunto de conhecimentos gerais mínimos para alfabetização 
em Computação, 3. Formação Tecnológica em Computação, um conjunto de conhecimentos específicos, formando um conjunto de disciplinas de alto teor tecnológico e de capacitação para o desenvolvimento profissional de produtos de soluções em Computação e 4. Formação Profissional Específica. Nesse item há uma pequena diferença, pois no curso de Cáceres, nele se incluem os conteúdos pedagógicos necessários à habilitação em licenciatura e formação do professor. No curso de Colíder corresponde a conteúdos multidisciplinares, que visam à formação em informática educativa; os conteúdos pedagógicos necessários à habilitação em licenciatura e formação do professor aparecem no eixo denominado Licenciatura.

Os cursos em análise possuem objetivos semelhantes, voltados para a formação de um educador qualificado para disseminar a cultura da informática, habilitando-o ao ensino, elaboração de projetos pedagógicos de informática e produtos educacionais condizentes com o contexto e necessidades atuais do país. No curso de Cáceres aparece como um dos objetivos "formar educador em Computação para atuar no mercado tecnológico e suprir demandas", não deixando claro a que mercado e demandas se refere (UNEMAT, 2007).

No PP do curso de Cáceres, o perfil de profissional almejado é assim descrito: "profissionais que estejam habilitados para atuar na área da informática educacional e com competência para desenvolvimento de projetos interdisciplinares e prestação de consultoria e assessoria no âmbito da informática" (grifo nosso). Houve uma adequação, no ano de 2006, e o texto que dizia: "O curso de Licenciatura Plena em Computação destina-se à formação de licenciados, capacitando-os para o exercício das funções ligadas ao ensino de Computação." foi substituído por:

O curso de Licenciatura Plena em Computação destina-se à formação de licenciados, capacitando-os para o exercício das funções ligadas ao ensino, treinamento, desenvolvimento de software e outros produtos ligados à informática educativa (UNEMAT, 2007, s/p).

O exercício da função de ensino de computação deixou de ter ênfase e a proposta passou a conter funções de treinamento e desenvolvimento de produtos ligados à informática. Esse perfil de profissional também está presente no PP do curso de Colíder, que caracteriza o Licenciado em Computação como: 
(...) um profissional dotado de conteúdos e habilidades para atuação no ensino fundamental, médio e profissionalizante,[...]. Além do exercício profissional de magistério em Computação na Educação Básica, e da capacitação na elaboração e aplicação de projetos de informática educativa, o egresso do curso terá ampla formação tecnológica, conceitual e prática, em Computação, habilitando-o ao desenvolvimento e implementação de produtos e soluções de informática voltados ao ensino e treinamento, desde um software educativo até sistemas de educação a distância assistida por computador" (UNEMAT, 2003, s/p).

Nesse caso, há ênfase nas atividades de ensino, mas não se descarta a possibilidade de atuação deste profissional em espaços não escolares.

Dois fatores podem explicar a definição ampla do campo de atuação do profissional da Computação e da informática: ainda não há uma regulamentação para a profissão e há variadas demandas em relação a seu trabalho. Porém, os cursos aqui analisados são de licenciatura, devendo, por princípio, formar professores. Pesquisas demonstram que cursos de licenciatura de outras áreas também têm previsto em seus PPs campos variados de atuação para seus profissionais, provavelmente na tentativa de corresponder à pressão do mercado ou de seduzir mais interessados (GENTIL, 2010). Nesse contexto, questiona-se a profissionalização do licenciado em computação: como se desenvolve a formação inicial sem que haja definição clara das "qualidades específicas, complexas e difíceis de serem adquiridas" para a essa formação profissional?

\section{0 estágio nos cursos de Licenciatura em computação: propostas e problemas}

A resolução no 038/2009/CONEPE estabelece as normas para a organização e funcionamento do Estágio Curricular Supervisionado dos Cursos e Graduação de Licenciatura Plena da UNEMAT e, em seu art. 3ㅇ, define o estágio como:

[...] o momento de efetivar, sob a orientação e supervisão do professor, um processo de ensino aprendizagem que possibilitará ao licenciando vivenciar e atuar em espaços escolares e não escolares (cujas atividades sejam voltadas à prática de ensino), preparando-o para a futura atuação profissional (UNEMAT, 2009, p.1).

Percebemos que os dois cursos, objeto de nossa análise, apesar de possuírem a mesma carga horária para o estágio (420 horas), possuem estruturas curriculares diferenciadas.

No curso de Colíder o estágio se divide em três etapas distintas, nos três últimos semestres. Parte da carga horária é destinada à contextualização do aluno referente às atividades a serem desenvolvidas, aulas teóricas e práticas para a elaboração do 
planejamento dos materiais para a regência de minicursos, socialização dos resultados, elaboração de relatório. E, aproximadamente, metade da carga horária é para práticas de observação e regência.

O Estágio Supervisionado do curso de Cáceres está dividido em quatro etapas, sendo 90 horas destinadas à disciplina de Estágio I, no 5o semestre, cuja ementa está voltada para:

(...) aquisição de competências relacionadas com o desempenho da prática dos alunos de Computação, [...], nos laboratórios da Universidade, nas escolas da rede pública e/ou privada, nas Instituições Sociais e empresas conveniadas. Compreende atividades de observações, pesquisas, acompanhamento da prática do profissional no mercado, assim como regências sobre técnicas, preparando-os para o exercício crítico e competente da docência, assim como coordenação de projetos (UNEMAT, $2007, \mathrm{~s} / \mathrm{p})$

O Estágio Supervisionado I do curso de Colider traz como foco principal a observação in-loco e regências de classe de minicursos profissionalizantes. Ambas as matrizes dão ênfase ao "acompanhamento da prática do profissional no mercado" e ao preparo para "o exercício crítico e competente da docência".

A segunda disciplina de estágio em Cáceres está voltada à "elaboração e criação de projetos pedagógicos multimídias, produções digitais para a Educação, soluções tecnológicas e acompanhamento de produção de empresas da região, sobretudo na área educacional." (UNEMAT, 2007, s/p). Tenta-se abranger as duas formações: a de professor e a de um profissional que atenda as demais demandas tecnológicas do mercado.

A matriz de Colíder permite propostas diferenciadas de estágio que "deverão ser analisadas pelo professor-supervisor e pelo coordenador e aprovadas pelo colegiado de curso." (UNEMAT, 2009, p.4), verificando se será benéfica à formação profissional do acadêmico. São projetos voltados para a recuperação de laboratórios de informática de escolas, estudo e aplicação de ambientes de aprendizagens, até desenvolvimento de softwares educacionais.

A disciplina de Estágio Supervisionado III, de Cáceres, é uma preparação para a prática pedagógica, com atividades de regência e de intervenção pedagógica e a ementa enfatiza que os espaços de atuação dos estagiários são os laboratórios de informática. Mais uma vez, se afirma a possível capacitação para o mercado técnico e se faz referência a outro mercado, que seria o pedagógico. 
(...) Compreende atividades de regência para docentes e discentes do ensino público e particular da região, envolvendo o Ensino Fundamental, Médio/Superior, Projetos Sociais e Formação de professores, com a utilização de ambientes significativos, que possam colaborar efetivamente com avanços na educação. Envolve também a elaboração e execução de projetos de intervenção pedagógica informatizados, aplicação e reelaboração do material educativo multimídia elaborado no estágio anterior, assim como envolvimento em soluções tecnológicas em ambientes coorporativos públicos ou privado. (...) contribuir para a melhoria das condições do desenvolvimento da educação, e capacitação profissional para o mercado técnico e pedagógico. (UNEMAT, 2007, s/p, grifo nosso).

No curso de Colíder os objetivos são semelhantes, mas o espaço de atuação do segundo estágio é a sala de aula do ensino fundamental. O acadêmico realiza observação in loco de aulas ministradas (junto ao professor regente de qualquer sala) e regência de classe voltada para a inclusão de recursos computacionais em matérias do currículo e/ou de formação básica em informática, para alunos e professores.

O último estágio em Colíder prevê observação e atuação em salas do ensino médio, com a inclusão de recursos computacionais em matérias do currículo, formação básica em informática e introdução à Computação, para os alunos e professores. Em Cáceres a ementa prevê o mesmo que para o estágio anterior, com aprofundamento.

A análise das propostas curriculares como um todo indica que as disciplinas de caráter mais pedagógico e educacional estão articuladas de modo a oferecer certa base para o estágio, mas com especificidades em cada local.

Nas matrizes curriculares, identificam-se propostas de estágio que visam a preparação do profissional para atuação nas escolas, mas sempre com ressalvas para uma possível atuação também fora do ambiente escolar. É como um reflexo do contexto contraditório em que surgem essas licenciaturas: uma demanda social por aprendizagem das novas TIC, a ausência de um locus determinado para esse ensino e a não delimitação de um campo profissional específico para esse professor.

De acordo com Silva (2010), os acadêmicos identificam como problema o fato de que os estágios ocorrem nos laboratórios de informática, onde não há um profissional professor licenciado em Computação com o qual possam dialogar ou trocar experiências de docência, que atue como orientador ou professor regente. Geralmente, contam com a presença de um técnico responsável pelo laboratório. 
As dificuldades de estágio no curso de licenciatura em Computação representam, de certo modo, as dificuldades dos profissionais e advém, em grande parte, do fato de essa profissão estar em processo de constituição. Em conclusão de trabalho de pesquisa, Silva (2010, p.35, grifo nosso) apresenta como síntese das opiniões de estagiários:

[...] a urgência de que se estabeleçam parcerias entre universidade e escola para que sejam criadas políticas que discutam o espaço profissional licenciado em Computação no mercado de trabalho. A falta de clareza sobre o espaço e a atuação do profissional licenciado em Computação ficou explícita nas dificuldades apontadas pelos entrevistados com relação a realização de seu estágio na escola.

O estágio é um momento representativo dos problemas em relação à profissão, posto que considerado espaço privilegiado de teoria/prática, de "experimento da realidade" por parte dos estudantes. Destaca-se como problemática a questão relativa ao espaço de atuação do licenciado em Computação na Educação Básica. As indagações persistem: se é uma disciplina inexistente na matriz curricular da educação básica, como ter um espaço de experiência definido, um grupo a quem dirigir as ações e um interlocutor da área? Por outro lado, se houve autorização para a criação dos cursos de licenciatura na área, questiona-se: há intenção de se inserir esse profissional no campo da educação ou de que essa área tenha o estatuto de disciplina na Educação Básica?

Desde a criação desses cursos estão sendo tomadas atitudes em favor de consolidar essa profissão e definir seu campo de atuação na educação, mas os resultados ainda são parciais. A UNEMAT fez um trabalho junto à Secretaria de Educação do Estado de Mato Grosso, no sentido de se priorizar o Licenciado em Computação para atuação nos laboratórios de informática das escolas, o que foi levado em conta na Portaria no 307/08/GS/Seduc/MT que trata da contratação de pessoal para laboratórios de informática, afirmando entre os critérios para a seleção de candidatos, ter curso ou estar cursando Licenciatura em Computação. Mas essa Portaria define a contratação de Técnico Administrativo Educacional e não a contratação de um professor.

Em Colíder, a vaga do laboratório de informática das escolas municipais está sendo ocupada por Licenciados em Computação, com salário compatível à formação acadêmica e, em 2012, a prefeitura publicou edital de concurso em que prevê 5 vagas para licenciados em computação. Essa não é a situação na maioria dos municípios mato-grossenses. Outra conquista importante foi a abertura de 51 vagas em concurso público no Estado de Mato 
Grosso (2010) para o cargo de professor da educação básica na área de informática educativa, conforme edital no 004/2009 da Secretaria de Administração.

\section{Considerações}

Partimos da compreensão de que profissionalização é processo contínuo de se fazer coletivamente, iniciado na graduação, no sentido de que a formação inicial sistematiza, propicia fundamentação na área específica de conhecimento, possibilita aperfeiçoamento das ações próprias do campo de trabalho, constitui espaço inicial de constituição da profissão, de reconhecimento social, status e prestígio.

$E$, nesse sentido, a profissionalidade enquanto aspecto subjetivo desse processo se desenvolve na medida em que se constitui uma identidade nessa profissão, uma possibilidade de significar coletivamente a partir de conhecimentos, valores, práticas, modos de fazer reconhecidos como seus.

Professor de Computação é um novo profissional, ainda luta por espaço delimitado de trabalho; é uma profissão que, segundo indicam os PPs analisados, almeja atender à demanda da sociedade contemporânea de profissionais flexíveis, aptos a atuar em mais de um campo de trabalho, enfim, uma profissão em busca de autoafirmação (profissionalidade/identidade).

Para além das ações que caracterizam a profissionalização em seu aspecto objetivo em desenvolvimento (cheio de conflitos, incompreensões e contradições), no que diz respeito à profissão professor em geral, há especificidades que não se pode deixar de lado e faz-se necessária maior atenção aos cursos de formação inicial, dada a sua importância nesse processo.

As análises feitas indicam possibilidade de aprofundamento sobre os documentos que orientam a formação do profissional em questão, para o que não haveria espaço neste artigo. O estudo realizado reafirma as preocupações iniciais: a constituição da profissionalidade não é algo imposto ou fixo; depende de vivências, de construção de significados e, para tanto, os cursos de graduação têm um papel importante a cumprir, 
precisando ter clareza em relação ao profissional que esperam formar e sua respectiva atuação.

\section{Referências}

AGUIAR, N. M. C. B de. O trabalhador docente frente às transformações na economia mundial e no contexto educacional. Revista da FAED, Cáceres, Ano VII, n. 12, p.121-131, jul./dez.2009.

ALMEIDA, M. E. B. de. Informática e Formação de professores. Brasília: Ministério da Educação, 2000. v. 2.

BRASIL. Ministério da Educação. Conselho Nacional de Educação. MEC/CNE. Resolução CNE/CP 1, de 18 de fevereiro de 2002. Institui Diretrizes Curriculares Nacionais para a Formação de Professores da Educação Básica, em nível superior, curso de licenciatura, de graduação plena. Brasília, DF, fev. 2002.

BRASIL/MEC/SESU/CEEInf. Diretrizes Curriculares para os cursos de Bacharelado em Ciência da Computação, Engenharia de Computação, Engenharia de Software e Sistemas de Informação e cursos de Licenciatura em Computação. Disponível em <http://formularios.mec.gov.br/consulta-diretrizes-curriculares>. Acesso em: 02 fev. 2011.

Diretrizes Curriculares de cursos da área de computação e informática. 2003.

Disponível em: <http://www.inf.ufrgs.br/ecp/docs/diretriz.pdf>. Acesso em: 02 fev. 2011.

BRASIL. Ministério da Educação. Secretaria de Educação Fundamental - MEC/SEF.

Parâmetros curriculares nacionais: introdução aos parâmetros curriculares nacionais.

Brasília: MEC/SEF, 1997. Disponível em: <portal.mec.gov.br/seb/arquivos/pdf/livro01.pdf>. Acesso em: 02 fev. 2011.

Ministério da Educação. Parâmetros Curriculares Nacionais para o Ensino Médio (PCNEM). Disponível em:

http://portal.mec.gov.br/index.php?id=12598:publicacoes\&option=com_content\&view=arti cle. Acesso em: 02 fev. 2011. 
CAMARGO, A. M. M. de; HAGE, S. M. A política de formação de professores e a reforma da educação superior. In: MANCEBO, D.; FÁVERO, M.L.A (Orgs.). Universidade: políticas, avaliação e trabalho docente. São Paulo: Cortez, 2004.

GENTIL, H. S. Analisando currículos de licenciaturas da UNEMAT/Cáceres: a formação de professores em questão. ENCONTRO DE PESQUISA EM EDUCAÇÃO DA ANPED CENTRO OESTE, 10, 2010, Uberlândia/MG. Anais... Uberlândia. ANPED CO, 2010. p. 01-10. 1 CD rom. ISSN: 2177- 4927.

KRAHE, E. D. Reforma Curricular e Licenciaturas: UFRGS (Brasil) - UMCE (Chile) - década de 1990. Porto Alegre: Editora da UFRGS, 2009.

LÜDKE, M. Caminhos da profissão e da profissionalidade docentes. Educ. Soc., Campinas, vol. 25, n. 89, p. 1159-1180, Set./Dez. 2004. Disponível em:

<http://www.cedes.unicamp.br>. Acesso em: 05 jan. 2011.

MATO GROSSO, Prefeitura Municipal de Colíder, concurso público. Edital n. o 001/2012 de 10 de fevereiro de 2012. Disponível em:

<http://www.colider.mt.gov.br/downloads_baixar.php?arquivo=Zm90b3NfZG93bmxvYWRzL zQ1ODcucGRm\&codigo=4587>. Acesso em: 20 fev. 2012.

MATO GROSSO/SEDUC/MT - SECRETARIA DE ESTADO DE EDUCAÇÃO DE MATO GROSSO. Portaria no 307/08/GS/Seduc/MT. Cuiabá, MT, de 07 de novembro de 2008. Disponível em: <http://www2.unemat.br/milhomem/files/dwl/doc/PORT_307_1_08_\%20ALTERA_257.pdf> . Acesso em: 28 jan. 2011.

NUNES, D. J. Licenciatura em Computação. Jornal da Ciência, Rio de Janeiro, n. 3522, s.p., mai. 2008. Disponível em: <http://www.jornaldaciencia.org.br/Detalhe.jsp?id=56398>. Acesso em: 10 mar. 2011.

RAMALHO, B. L.; NUÑEZ, I. B.; GAUTHIER, C. Formar o professor, profissionalizar o ensino: perspectivas e desafios. 2. ed.Porto Alegre: Sulina, 2004.

SACRISTÁN, J. G. Consciência e aç̧ão sobre a prática como libertação profissional dos professores. In: NÓVOA, A. (Org.). Profissão professor. Porto: Porto, 1995. 
SETTE, S. S.; AGUIAR, M. A.; SETTE, J. S. A. Licenciatura em informática: uma questão em aberto. Revista Brasileira de Informática na Educação, Florianópolis, v.1, n. 1, p.95-100, jul. 1997. ISSN 1414-5685

SILVA, C. de C. Formação do licenciado em computação. In: CONGRESSO DE INICIAÇÃO CIENTÍFICA DA UNEMAT, 6, Cáceres, 2010. Anais... Cáceres: UNEMAT, 2010. p.01-10. 1 CD, ISSN: 2178-7492.

SOCIEDADE BRASILEIRA DE COMPUTAÇÃO. Distribuição de Matérias Componentes das Diretrizes Curriculares: Abrangência e profundidade das disciplinas de cada matéria do currículo de referência - cursos de Licenciatura em Computação. 2002. Disponível em: $<$ http://portal.sbc.org.br/educacao/lib/exe/fetch.php?media=documentos:licenciatura2002.pdf> . Acesso em: 28 jan. 2011.

TAJRA, S. F. Informática na Educação: novas ferramentas pedagógicas para o professor na atualidade. 8 ed. São Paulo: Érica Ltda., 2008.

UNEMAT. CONEPE. Resolução no $\mathbf{0 3 8} / \mathbf{2 0 0 9}$, de 26 de maio de 2009. Normas para a organização e funcionamento do Estágio Curricular Supervisionado dos Cursos de Graduação de Licenciatura da UNEMAT. Cáceres, MT, maio 2009.

Resolução no 201/2006. Estabelece normas para a organização e funcionamento do Estágio Curricular Supervisionado do Curso de Licenciatura Plena em Computação do Campus Universitário do Vale do Teles Pires em Colíder/MT. Cáceres, MT, dez. 2006.

Resolução no 230/2003 de 24 de outubro de 2003. Aprova o Projeto Pedagógico do Curso de Licenciatura em Computação do Campus Universitário do Vale do Teles Pires em Colíder. Cáceres, MT, out.2003

UNEMAT. Departamento de Licenciatura em Computação do Campus de Cáceres. Processo de renovação do reconhecimento do curso de Licenciatura Plena em Computação. Cáceres, MT, 2007. 